\title{
Determination of sorption properties of micropollutants: What is the most suitable activated sludge inhibition technique to preserve the biomass structure?
}

\author{
Pierre Hamon, Maud Villain, Benoît Marrot* \\ Aix-Marseille Université, CNRS, M2P2 UMR 7340, 13545 Aix en Provence, France
}

Apart from providing a total activated sludge (AS) inhibition, an efficient AS inhibition technique must preserve the biomass structure in order to maintain the real sorption phenomenon. Many inhibition techniques with different modes of action were used in previous studies for AS inhibition. But, the effectiveness of AS deactivation and the adverse effects on the biomass structure were rarely related. In this paper, five common AS inhibition techniques were evaluated: thermal, three chemical and gas purging techniques. The lowest chemical effective concentrations were determined in order to limit the negative impact on the AS structure. $100 \mathrm{mgHg}_{2} \mathrm{SO}_{4} \mathrm{~g}_{\mathrm{TSS}}{ }^{-1}$ and $30 \mathrm{mgHgCl}_{2} \mathrm{~g}_{\mathrm{TSS}}{ }^{-1}$ within $2 \mathrm{~h}$ of reaction were enough to provide a complete AS inhibition. However, after $20 \mathrm{~h}$ of reaction a full AS inhibition has never been achieved with sodium azide at $200 \mathrm{mgNaN}_{3} \mathrm{~g}_{\mathrm{TSs}}{ }^{-1}$, even by increasing $\mathrm{NaN}_{3}$ concentration.

The analysis of the AS apparent viscosity, the median size $\mathrm{D}_{50}$ of the flocs and the supernatant turbidity showed that the thermal technique destructured the AS completely. A significant AS deflocculation is induced by the three chemical reagents depending on the mode of action and the concentration used. Thermal and chemical inactivations are therefore not suitable to determine sorption properties. The only technique which kept the initial AS structure unchanged has several drawbacks since (i) a reaction might occur between the gas and the analyte of interest, and (ii) anaerobic activated sludge are not inhibited by this technique. Therefore, the establishment of anaerobic conditions without gas injection is recommended for implementing sorption experiments on aerobic AS.

Keywords:Activated sludge inhibition Sorption, Activated sludge structure Deflocculation, Azide, Respiration

\section{Introduction}

In biological wastewater treatment plants (WWTPs) pollutants can theoretically be removed through several mechanisms: biotransformation, sorption to the activated sludge (AS) flocs, air-stripping and phototransformation. Biotransformation and sorption were reported as the two most important removal

\footnotetext{
* Corresponding author. Tel.: +334912893 07; fax: +33442908515

E-mail address: benoit.marrot@univ-amu.fr (B. Marrot).
}

mechanisms for pharmaceuticals [1]. Indeed, phototransformation is limited by the high turbidity of the mixed liquor, which blocks sunlight and removal by air-stripping depends on Henry coefficient of the pollutant.

The partitioning between biotransformation and sorption is commonly evaluated by inhibiting the AS in order to avoid biotransformation mechanism. Thereafter, the sorption properties are determined by adding the pollutant into the inactivated biomass. The removal in the liquid phase is solely attributed to the sorption mechanism. Many different AS inhibition techniques 
were used in previous studies with different modes of actions: chemical, physical, gas purging, sterilisation and freeze-drying. A correct assessment of sorption properties requires a total bacterial activity inhibition to avoid any pollutant biotransformation along with no adverse effect on the AS structure induced by the inhibition technique. An incomplete AS inhibition would involve biotransformation of the target compound and AS deflocculation could offer more possibilities for the pollutant to sorb on the AS. Thus, the mixed liquor chemistry must remain unchanged after application of the inhibition technique. It was demonstrated that a $\mathrm{pH}$ modification could induce a speciation of some molecules which have basic or acidic functionalities, in a more or less hydrophobic form that affects their sorption affinities [2]. The mixed liquor conductivity must remain constant as well, since the adsorption mechanism is based on electrostatic interactions.

However, the effects of the inhibition techniques were rarely evaluated in previous studies, except for sodium azide [3-6] and different chemical biocides [7]. These studies showed that sodium azide, a chemical reagent used in many works to determine sorption properties, has an impact on the AS apparent viscosity [3,5], on the sludge-water distribution of several compounds [4] as well as on the AS conductivity [7]. Sodium azide might also react with the analyte of interest and its use for sorption experiments must be carefully evaluated, especially for concentrations higher than $100 \mathrm{mg}_{\mathrm{NaN} 3} \mathrm{~L}^{-1}$ [6]. There does not seem to be any consensus about the reliability of chemical deactivation to determine sorption properties. Indeed, some authors assume that chemical reagents might have an influence on the sorption processes due to the inactivation of cells and the consecutive cell lysis or because of the possible reaction with the target compounds [6,8], whereas other works reported that sodium azide addition was not inducing cell lysis [9] or polysaccharides releases [3].

As far as chemical inhibition is concerned no clear inhibition protocols, except for sodium azide [3], and validation of the methods have been reported. The concentration and inhibition kinetic were rarely mentioned and only few information reported the AS inhibition state. In addition, the inhibitor concentrations are not always related to the same parameters (biomass concentration, weight ratio, volumetric ratio).

Regarding this situation, the aim of this study was to compare different chemical inhibitors with alternative inhibition techniques in order to suggest the most appropriate inhibition technique to determine the sorption properties. The optimal parameters of each selected inhibition technique were determined in order to reach a sufficient inhibition state and to limit the impact on the biomass structure. Among the alternative AS inhibition techniques freezedrying (lyophilisation) and autoclaving (sterilisation) were not evaluated in the present work since they were previously reported to alter the texture of sludge flocs and thus the sorbent structure $[10,11]$. AS sterilisation is carried out in an autoclave at $120^{\circ} \mathrm{C}$ for $30 \mathrm{~min}$. Freeze-drying is applied at a vacuum pressure of 0.5 mbar and a temperature of $-40{ }^{\circ} \mathrm{C}$.

Three different chemical inhibitors used in previous studies were selected: sodium azide $\left(\mathrm{NaN}_{3}\right)[3-5,7,9,12,13]$, mercury sulphate $\left(\mathrm{Hg}_{2} \mathrm{SO}_{4}\right)$ [14-16] and mercury chloride $\left(\mathrm{HgCl}_{2}\right)$ [17]. Sodium azide was also frequently used to inhibit microbial degradation in order to assess sorption properties of environmental contaminants to soil $[18-21]$. The alternative inhibition techniques were based on thermal and gas purging inhibition processes. The thermal technique applied basically consists in drying the sludge by heating $[22,23]$. The gas purging technique consists in injecting a gas into AS in order to force oxygen out and was used in few studies with argon [24] and nitrogen [25,26]. None of these studies stated on the reliability of these AS inhibition techniques to determine sorption properties.

\section{Material and methods}

\subsection{Activated sludge}

The activated sludge (AS) came from an urban wastewater treatment plant (Aix-en-Provence, France, 175,000 eq. inh., $35,000 \mathrm{~m}^{3} \mathrm{~d}^{-1}$, organic load $0.12 \mathrm{~kg}_{\text {BoD } 5} \mathrm{~kg}_{\mathrm{Mvs}}{ }^{-1} \mathrm{~d}^{-1}$ ). Samples were taken from the recirculation loop between the aeration tanks and the secondary clarifiers and were then transported to the laboratory with no aeration $(30 \mathrm{~min})$. The initial total suspended solids (TSSs) concentration varied from 3.5 to $5.1 \mathrm{~g} \mathrm{~L}^{-1}$. The amount of volatile suspended solids varied from $76 \%$ to $80 \%$ for all the experiments. The AS was concentrated by gravimetric filtration using paper filters (average size pores around $100 \mu \mathrm{m}$ ) in order to obtain a TSS content of $10 \pm 1 \mathrm{~g} \mathrm{~L}^{-1}$. Before any experiment was performed, sludge was aerated during $4 \mathrm{~h}$ without substrate addition and the oxygen uptake rate (OUR) of small samples was monitored to ensure endogenous respiration state.

\subsection{Respiration inhibition}

Activated sludge respirometry was monitored by the OUR calculation. Air injection is stopped and the decreasing dissolved oxygen concentrations were recorded every $10 \mathrm{~s}$. The OUR is the value, which corresponds to the slope of the linear decrease of the oxygen concentration over time. The specific oxygen uptake rate (SOUR) relates the OUR depending on the mixed liquor volatile suspended solids concentration (MLVSS). A SOUR null value means that the AS inhibition state is reached because microorganisms cannot consume the dissolved oxygen. The inhibition state of the biomass was then monitored by calculating the SOUR drop for the five inhibition techniques in comparison to the initial SOUR of the AS. The dissolved oxygen concentration was measured with continuous oxygen probe (HQ 40d, Hach LDO, Germany).

\subsection{Chemicals}

Sodium azide $\left(\mathrm{NaN}_{3}, 99 \%\right.$, Sigma-Aldrich), mercury chloride $\left(\mathrm{HgCl}_{2}, 99.5 \%\right.$, Sigma-Aldrich) and mercury sulphate $\left(\mathrm{Hg}_{2} \mathrm{SO}_{4}\right.$, $99 \%$, Chem-Lab) were used as chemical inhibitors.

\subsection{Thermal technique}

The Thermal inhibition technique simply consists in drying the sludge. In this paper the protocol applied for thermal inhibition was established by Delgado [22]. AS is firstly centrifuged during $20 \mathrm{~min}$ at $5000 \mathrm{rpm}$. Solids are collected and rinsed with distilled water in order to reduce the amount of exopolymeric substances. The clean sludge is then centrifuged again during $20 \mathrm{~min}$. The sludge is dried at $80^{\circ} \mathrm{C}$ during 2 days to ensure the inactivation and the complete drying. The biomass is finally ground until obtaining a uniform size of grains.

The grains are put in a batch reactor with the AS supernatant to reach a concentration of $10 \mathrm{~g}_{\text {TSS }} \mathrm{L}^{-1}$. Solubilisation of the grains could not be reached after a long stirring time, the mixture remained completely heterogeneous. SOUR measurement indicated that the complete AS inhibition was achieved.

\subsection{Gas purging technique}

The inhibition protocol used in this study was based on the method developed by Seira et al. [25]. Firstly, oxygen was injected into AS to remove the residual substrates. Then, the aeration was stopped in order to remove the nitrates under anoxia conditions. Finally, nitrogen gas was injected to AS in order to force oxygen 
out. The dissolved oxygen concentration quickly reached a null value, avoiding AS respiration.

\section{6. $\mathrm{COD}$ and $\mathrm{NH}_{4}^{+}$degradation tests}

$800 \mathrm{mg} \mathrm{L}^{-1}$ (180 $\mathrm{mg} \mathrm{g}_{\mathrm{TsS}^{-1}}$ ) of chemical oxygen demand (COD) as glucose and $50 \mathrm{mg} \mathrm{L}^{-1}\left(12 \mathrm{mg} \mathrm{g}_{\mathrm{TSS}}{ }^{-1}\right)$ of ammonium were added to the inhibited biomass during $2 \mathrm{~h}$ under aeration in order to assess the effectiveness of each inhibition technique on the removal of easily biodegradable compounds. COD and ammonium were chosen to distinguish the efficiency of the inhibition techniques on heterotrophic and autotrophic bacteria. Substrate degradation would show an incomplete inhibition of the related bacteria population.

\subsection{Bioreactor and rheological devices}

The bioreactor was equipped with a double helical ribbon impeller (HRI) and filled with a volume of $1.9 \mathrm{~L}$ of activated sludge. The impeller had a $9.5 \mathrm{~cm}$ diameter and height each, while the bioreactor was $12 \mathrm{~cm}$ in diameter. Sludge temperature was maintained constant at $20 \pm 1{ }^{\circ} \mathrm{C}$ with water circulating in a double envelope.

To perform the in situ viscosity curves determination of AS suspensions, the HRI of the bioreactor was connected to a shear rate imposed rheometer (Rheomat 30, Contraves) with 30 available values of the imposed rotation speed in the range $0.408-257 \mathrm{rpm}$. The stirring torque was measured for each value of the rotation speed.

Before each torque measurement, the suspension was presheared at the maximum rotation speed for $30 \mathrm{~s}$ to ensure its homogeneity. The rotation speed was then decreased to the desired value and the torque was recorded for $15 \mathrm{~s}$ after $15 \mathrm{~s}$ of stabilisation.

Viscosity calculations were performed with Metzner-Otto's principle. It defines an apparent viscosity $\eta_{a}$ (Pa s) based on the generalization for non-Newtonian media of the relationship in an agitated vessel (in the laminar region) between the dimensionless power Np and the Reynolds number Re (Eq. (1)):

$N_{p}=\frac{P}{\rho \cdot N^{3} \cdot d^{5}}=\frac{K_{p}}{R e}=\frac{K_{p} \cdot \eta_{a}}{\rho \cdot N \cdot d^{2}}$ then $\eta_{a}=\frac{P}{K_{p} \cdot N^{2} \cdot d^{3}}$

where $P(\mathrm{~W})$ is the mechanical stirring power related to the agitation torque $C(\mathrm{~N} \mathrm{~m})$ and to the mechanical rotation rate $N\left(\mathrm{~s}^{-1}\right)$ by the following equation:

$P=2 \cdot \pi \cdot N \cdot C$

$K_{p}$ corresponds to the laminar power curve constant and $d(\mathrm{~m})$ to the impeller diameter.

At a rotation rate $N$ corresponds an effective shear rate $\gamma_{\mathrm{MO}}\left(\mathrm{s}^{-1}\right)$ related to the rotation speed of the impeller by the Metzner-Otto dimensionless constant characterising the stirrer geometry (Eq. (3))

$\gamma_{\mathrm{MO}}=K_{\mathrm{MO}} \cdot N$

Values of $K_{p}$ and $K_{\mathrm{MO}}$ constants have been determined at respectively 393 and 50 . A calibration of the set-up was carried out for a previous paper [27] with two model fluids at $20^{\circ} \mathrm{C}$ to determine the $K_{p}$ and $K_{\mathrm{MO}}$ constants. The fluids used were a Newtonian solution of pure glycerol and an aqueous solution of guar at 1 wt.\%.

The Ostwald power law model (Eq. (1)) has been used to represent the viscosity curves of initial and inhibited AS.

$\tau=K \gamma^{n}$
Both parameters of this model, i.e. the consistency index ( $K$ in $\mathrm{Pa}^{\mathrm{n}}$ ) and flow index (n) were calculated with a simple linear regression log-log scale.

Three measurements of the rheological profile were carried out to ensure the data reproducibility.

\subsection{Analytical methods}

TSS were measured by centrifugation of a $30 \mathrm{~mL}$ sludge sample for $15 \mathrm{~min}$ at $13,500 \mathrm{rpm}$ followed by pellet drying at $105^{\circ} \mathrm{C}$ until a constant weight was obtained ( $24 \mathrm{~h}$ ). TVSS were measured after 2 h at $550^{\circ} \mathrm{C}$.

The degree of sludge deflocculation was estimated by the method presented by Wilén et al. [28]. Samples of AS were taken during the inhibition reaction and centrifuged at $2000 \mathrm{rpm}$ for $2 \mathrm{~min}$. Supernatant turbidity was then measured as the absorbance at $650 \mathrm{~nm}$.

Particle size distribution of AS was measured with a laser granulometer Mastersizer S (Malvern Instruments). It measures particle size from $0.1 \mu \mathrm{m}$ to $900 \mu \mathrm{m}$. The median size $\left(D_{50}\right)$ was recorded for every AS inhibition technique. The filtrate of the mixed liquor recovered after AS concentration was used to dilute 100 times the inhibited AS samples in order to obtain an acceptable obscuration allowing the particle size distribution measurement. Three measurements of particle size distribution and the supernatant turbidity were carried out to ensure the data reproducibility.

$\mathrm{pH}$ and conductivity of the mixed liquor were measured for initial AS and for every inhibition techniques.

\section{Results and discussion}

\subsection{Determination of optimum chemical inhibitor concentrations}

Very little information is provided in the literature about chemical inhibitor parameters. There is no consensus about inhibitor concentration units. In this paper the expression of inhibitor concentrations was standardised into $\mathrm{mg}_{\text {inhibitor }} \mathrm{g}_{\mathrm{TSS}}{ }^{-1}$. Inhibitor concentrations used in previous studies were converted into $\mathrm{mg}_{\text {inhibitor }} \mathrm{g}_{\mathrm{TSS}}{ }^{-1}$ when enough data were available in the papers (Table 1). As it can be seen in this table, there is also no consensus on the chemical concentration used for AS inhibition.

Concerning sodium azide a wide range of concentrations, from $0.5 \mathrm{mg} \mathrm{g}_{\mathrm{TSS}^{-1}}{ }^{\text {[4] }}$ to $720 \mathrm{mg} \mathrm{g}_{\mathrm{TSS}}{ }^{-1}$ [5], were used in previous studies for AS inhibition. However, sodium azide was previously reported to alter biomass viscosity [3,5]. It is coherent to assume that if chemical reagents induce negative effects to the AS structure, increasing the chemical concentration would emphasize the impact on AS structure. This hypothesis was confirmed by preliminary rheological measurements carried out at different sodium azide concentrations (Fig. 1). An increase in the sodium azide concentration caused a lower AS viscosity. Thereby, the lowest effective chemical concentrations were firstly determined before comparing the impact of each inhibition technique with the AS structure.

Therefore, it is required to find for each chemical inhibitor the lowest concentration at which the complete inhibition is achieved in order to limit alteration of the AS structure. Working at the lowest effective chemical inhibitor concentration makes it possible to compare the different inhibition techniques with each other equally.

\subsubsection{Sodium azide}

Only little information is generally mentioned by the authors about the inhibition parameters and the reliability of the method (Table 1), except for Barbot et al. [3] who tested 3 sodium azide 
Table 1

Chemical inhibitor concentrations used in previous studies.

\begin{tabular}{|c|c|c|c|c|}
\hline Inhibition information & $\begin{array}{l}\text { Calculated } \\
\text { concentration }\end{array}$ & $\begin{array}{l}\text { Reaction } \\
\text { time }\end{array}$ & Comments & References \\
\hline \multicolumn{5}{|l|}{$\mathrm{NaN}_{3}$} \\
\hline $0.2 \% \mathrm{w} / \mathrm{w}$ & $2 \mathrm{mg} \mathrm{g}_{\mathrm{TSS}^{-1}}$ & - & $\begin{array}{l}\text { "based on respirometry measurement, without any cell lysis or any change in } \\
\text { the sludge hydrophobicity" }\end{array}$ & [8] \\
\hline- & - & - & - & [9] \\
\hline $0.2 \% \mathrm{v} / \mathrm{v}$ & - & - & No information on the sodium azide solution concentration $-\mathrm{TSS}=9.01 \mathrm{~g} \mathrm{~L}^{-1}$ & [10] \\
\hline $0.9 \mathrm{~g} \mathrm{~g}_{\mathrm{MVLSS}^{-1}}$ & $720 \mathrm{mg} \mathrm{g}_{\mathrm{TsS}^{-1}}$ & - & $\begin{array}{l}\text { Inhibition of the respirometry activity. "no polysaccharide release, viscosity } \\
\text { was reduced of around } 40 \% \text { but did not modify activated sludge sorption } \\
\text { abilities" }\end{array}$ & [4] \\
\hline $200 \mathrm{mg} \mathrm{g}_{\mathrm{TSS}^{-1}}$ & - & $4 \mathrm{~h}$ & $\begin{array}{l}\text { Inhibition of around } 90 \% \text { after } 4 \mathrm{~h} .0 .1 \text { et } 0.35 \mathrm{~g} \mathrm{~g}_{\mathrm{TSS}}{ }^{-1} \text { also tested. Decrease of } \\
\text { the apparent viscosity }\end{array}$ & [2] \\
\hline $\begin{array}{l}190 \mathrm{~mL} \text { sludge }-\mathrm{TSS}=4 \mathrm{~g} \mathrm{~L}^{-1} \\
\quad[\mathrm{NaN} 3]=0.2 \% \text { and } 1 \%\end{array}$ & $\begin{array}{l}0.5 \mathrm{mg} \mathrm{g}_{\mathrm{TSS}}{ }^{-1} \\
\text { and } \\
2.5 \mathrm{mg} \mathrm{g}_{\mathrm{TSS}}{ }^{-1}\end{array}$ & - & $\begin{array}{l}\text { Adverse effects of sodium azide on the sludge-water distribution of several } \\
\text { compounds }\end{array}$ & [3] \\
\hline \multicolumn{5}{|l|}{$\mathrm{Hg}_{2} \mathrm{SO}_{4}$} \\
\hline $\begin{array}{l}0.5 \mathrm{~mL} \mathrm{~L}_{\text {sludge }}{ }^{-1}-\left[\mathrm{Hg}_{2} \mathrm{SO}_{4}\right]=200 \mathrm{~g} \mathrm{~L}^{-1}- \\
0.1 \mathrm{~g}_{\mathrm{Hg} 2 \mathrm{SO} 4} \mathrm{~L}_{\text {sludge }}{ }^{-1}-\mathrm{TSS}=1-3-5- \\
\quad 7 \mathrm{~g} \mathrm{~L}^{-1}\end{array}$ & $\begin{array}{l}14-20-33- \\
100 \mathrm{mg} \mathrm{g}_{\mathrm{TSS}}^{-1}\end{array}$ & - & - & [11] \\
\hline $\begin{array}{l}{\left[\mathrm{Hg}_{2} \mathrm{SO}_{4}\right] \text { solution }=0.2 \mathrm{~g} \mathrm{~L}^{-1}-} \\
\quad \mathrm{TSS}=1 \mathrm{~g} \mathrm{~L}^{-1}\end{array}$ & - & - & - & [12] \\
\hline $\begin{array}{l}1 \mathrm{~mL} \mathrm{Hg}_{2} \mathrm{SO}_{4} \text { to } 200 \mathrm{~mL}_{\text {sludge }}- \\
\quad\left[\mathrm{Hg}_{2} \mathrm{SO}_{4}\right]=20 \mathrm{~g} \mathrm{~L}^{-1}-\mathrm{TSS}=15 \mathrm{~g} \mathrm{~L}^{-1}\end{array}$ & $6.7 \mathrm{mg} \mathrm{g}_{\mathrm{TSS}^{-1}}^{-1}$ & - & - & [13] \\
\hline $\begin{array}{l}\mathrm{HgCl}_{2} \\
100 \mathrm{mg}_{\mathrm{HgCl} 2} \mathrm{~L}_{\text {sludge }}{ }^{-1}- \\
\quad \text { Xbiomass }=6.2 \mathrm{~g}_{\mathrm{COD}} \mathrm{L}^{-1}- \\
\quad \mathrm{TSS}=5.46 \mathrm{~g} \mathrm{~L}^{-1}\end{array}$ & $18.3 \mathrm{mg} \mathrm{g}_{\mathrm{TSS}^{-1}}$ & - & $\begin{array}{l}\mathrm{HgCl}_{2} \text { has a smaller influence than sliver nitrate on the measurements of the } \\
\text { investigated compounds }\end{array}$ & [14] \\
\hline
\end{tabular}

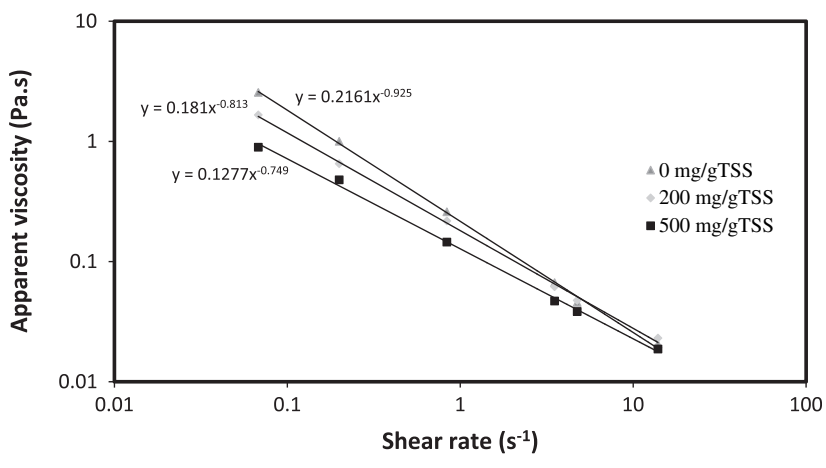

Fig. 1. Influence of azide concentration on the apparent viscosity of AS.

concentrations: $100-200-350 \mathrm{mg} \mathrm{g}_{\mathrm{TSS}^{-1}}$. In this study the maximum inhibition state of the microorganism respiration was obtained after addition of $\mathrm{NaN}_{3}$ at $200 \mathrm{mg} \mathrm{g}_{\mathrm{TSS}}{ }^{-1}$.

Five sodium azide concentrations were tested in this paper: the two drastic concentrations 0.5 and $720 \mathrm{mg} \mathrm{g}_{\mathrm{TSS}}{ }^{-1}$ and three concentrations $200-250-300 \mathrm{mg} \mathrm{g}_{\mathrm{TSS}}{ }^{-1}$ in order to ripen the optimum concentration found by Barbot et al. [3].

No AS inhibition was observed at $0.5 \mathrm{mg} \mathrm{g}_{\mathrm{TSS}^{-1}}$, this concentration being totally insufficient to impact biomass respiration. For the three concentrations $200-250-300 \mathrm{mg} \mathrm{g}_{\text {TSS }}{ }^{-1}$ a $90 \%$ inhibition state has never been achieved after $4 \mathrm{~h}$ of reaction contrary to Barbot et al. [3]. $20 \mathrm{~h}$ were required in some experiments to reach a SOUR drop about 90\% (Fig. 2). Furthermore, a poor repeatability of the results was observed, indicating that AS inhibition by sodium azide might depend on other AS parameters, such as AS initial activity or AS structure. AS inhibition with the very high sodium azide concentration ( $720 \mathrm{mg} \mathrm{g}_{\mathrm{TSS}^{-1}}{ }^{-1}$ ) was never above $84 \%$, even after $20 \mathrm{~h}$ of reaction. It is noticeable that, in the range of the tested concentrations, an increase in the sodium azide concentration was not linked with a higher AS inhibition, meaning that beyond a threshold concentration no better AS inhibition could be reached with sodium azide.

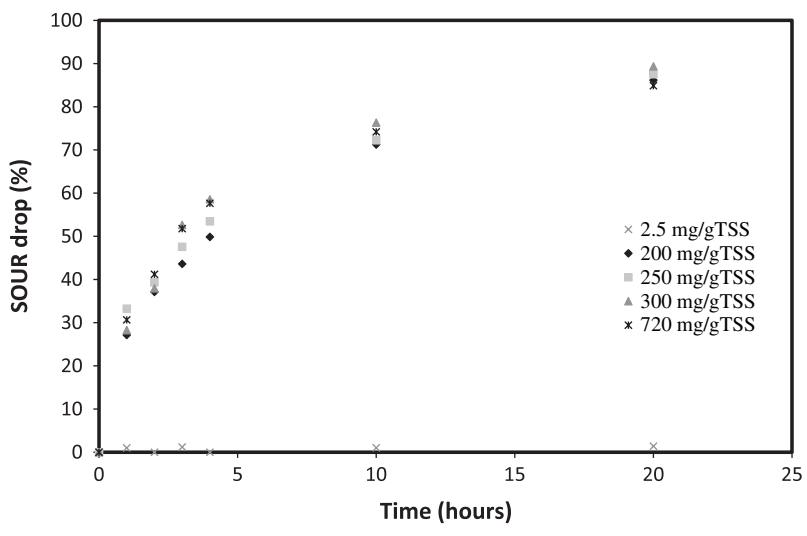

Fig. 2. SOUR drop at different sodium azide concentrations.

Therefore, sodium azide seems to be inappropriate to inhibit AS because it is impossible to suggest a concentration and a reaction time allowing the achievement of a complete and systematic AS inhibition state. The concentration $200 \mathrm{mgNaN}_{3} \mathrm{~g}_{\mathrm{TSS}}{ }^{-1}$ was chosen to conduct the biomass structure comparison as no significantly better AS inhibition was achieved at higher concentrations.

\subsubsection{Mercury sulphate}

$\mathrm{Hg}_{2} \mathrm{SO}_{4}$ concentrations used in previous works were much lower than sodium azide concentrations (Table 1 ). Three concentrations of $\mathrm{Hg}_{2} \mathrm{SO}_{4}$ were tested according to the concentrations of Clara et al. [14]: $10-50-100 \mathrm{mg} \mathrm{g}_{\mathrm{TSS}}{ }^{-1}$ (Fig. 3). Concentrations of 10 and $50 \mathrm{mg} \mathrm{g}_{\mathrm{TSS}^{-1}}{ }^{-1}$ provided a good AS inhibition but not complete for every test. A total AS inhibition was achieved at $100 \mathrm{mg} \mathrm{g}_{\text {TSS }^{-1}}$ in the two first hours of reaction for each test.

At half concentration and for a lower reaction length than for sodium azide the AS inhibition was complete, which indicates a different mode of action in the inhibition process. The concentration $100 \mathrm{mg}_{\mathrm{Hg} 2 \mathrm{SO} 4} \mathrm{~g}_{\mathrm{TSS}}{ }^{-1}$ was chosen for the biomass structure comparison. 


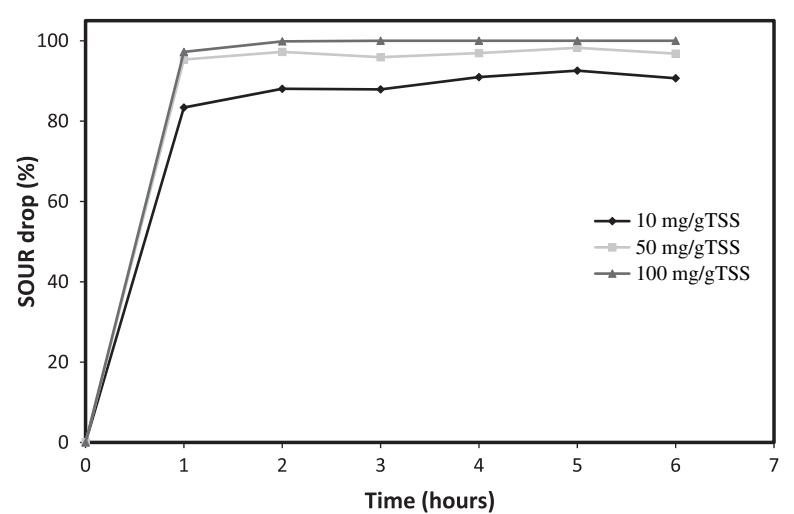

Fig. 3. SOUR drop at different mercury sulphate concentrations.

\subsubsection{Mercury chloride}

Only one study using $\mathrm{HgCl}_{2}$ to inactivate biomass has been found [17]. Because of the lack of studies, the concentration tests of $\mathrm{HgCl}_{2}$ were arbitrary set at the same concentration as for $\mathrm{Hg}_{2} \mathrm{SO}_{4}: 10-50-100 \mathrm{mg} \mathrm{g}_{\mathrm{TSS}^{-1}}{ }^{-1}$ (Fig. 4). The concentration of $10 \mathrm{mg} \mathrm{g}_{\text {TSS }}{ }^{-1}$ provided a good AS inhibition but not complete for each test, whereas a complete and systematic AS inhibition was achieved at 50 and $100 \mathrm{mg} \mathrm{g}_{\text {TSS }}{ }^{-1}$ in the two first hours of reaction. A concentration of $30 \mathrm{mg} \mathrm{g}_{\text {TSS }}{ }^{-1}$ was tested to ripen the optimum concentration and provided a complete AS inhibition in the two first hours of reaction for each test. Mercury toxicity is known to depend on its chemical form. Therefore, the lower concentration of $\mathrm{HgCl}_{2}$, in comparison with $\mathrm{Hg}_{2} \mathrm{SO}_{4}$, required inhibiting AS can be explained by the fact that mercury toxicity depends on its chemical form. The mercury (II) cation is much more toxic than the mercury (I) cation. Thus, the concentration $30 \mathrm{mg}_{\mathrm{HCl} 2} \mathrm{~g}_{\mathrm{TSS}}{ }^{-1}$ was chosen for biomass structure comparison.

\subsection{Effect of activated sludge inhibition on the biomass structure}

To assess the effect of each inhibition technique on the biomass structure, the rheological profile, the supernatant absorbance and the median size $D_{50}$ of sludge suspension were measured for the initial AS sample and for every inhibition technique when AS was considered in the inhibition state (Figs. 5 and 6 and Table 3), i.e. $2 \mathrm{~h}$ for $\mathrm{Hg}_{2} \mathrm{SO}_{4}$ and $\mathrm{HgCl}_{2}, 20 \mathrm{~h}$ for $\mathrm{NaN}_{3}$.

The viscosity curve of the thermal inhibition technique was not represented in Fig. 5 since no rotation torque could be measured by the experimental set-up at the shear rates tested in the laminar region. Indeed, the dried and ground sludge could not solubilise at all into the supernatant and resulted in two distinctive phases, which caused an irreversible effect on the AS structure.

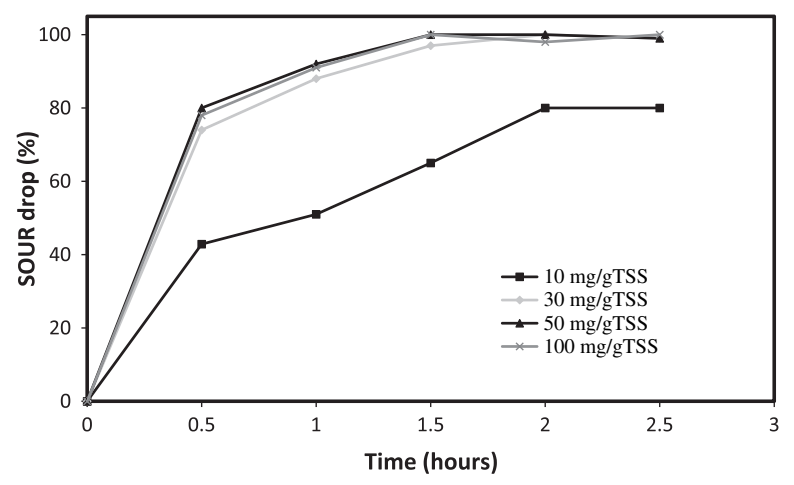

Fig. 4. SOUR drop at different mercury chloride concentrations.

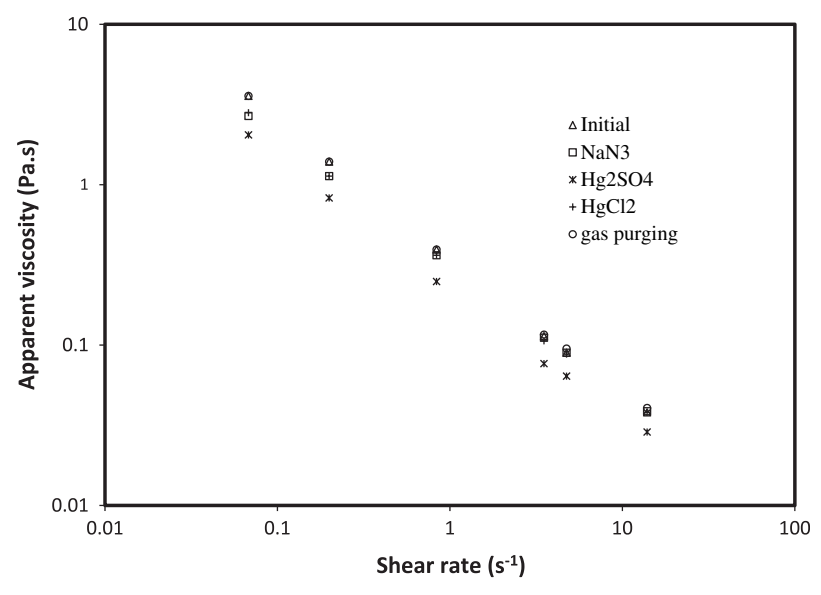

Fig. 5. Rheological behaviour of inhibited AS with the optimal chemical concentrations and the gas purging technique.

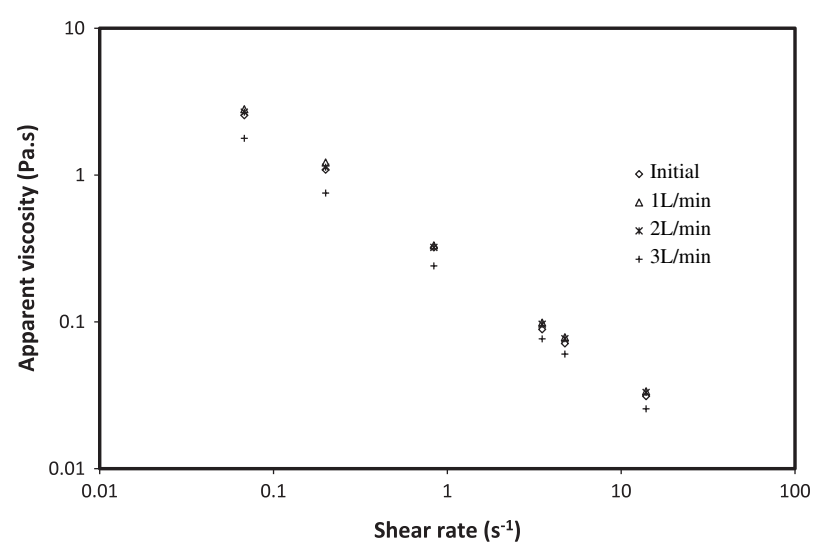

Fig. 6. Influence of $\mathrm{N}_{2}$ flow rate on the activated sludge viscosity.

A decrease of the AS apparent viscosity is induced by the three chemical methods. At the concentrations tested to ensure biomass inhibition, $\mathrm{NaN}_{3}$ and $\mathrm{HgCl}_{2}$ have the same impact on the apparent viscosity whereas $\mathrm{Hg}_{2} \mathrm{SO}_{4}$ causes a more significant drop-off. Mercury inhibitors seem to have a stronger impact on the bioflocs structure than sodium azide although $\mathrm{NaN}_{3}$ is 6.7 times more concentrated than $\mathrm{HgCl}_{2}$. AS apparent viscosity differences between $\mathrm{Hg}_{2} \mathrm{SO}_{4}$ and $\mathrm{HgCl}_{2}$ could be attributed to the higher concentration of $\mathrm{Hg}_{2} \mathrm{SO}_{4}$ required for AS inhibition.

The Ostwald law parameters confirm these observations (Table 2): a $10 \%$ decrease of the consistency index $\mathrm{K}$ is induced by $\mathrm{NaN}_{3}$ and $\mathrm{HgCl}_{2}$ additions at inhibiting concentrations whereas a $35 \%$ decrease of $\mathrm{K}$ is induced by $\mathrm{Hg}_{2} \mathrm{SO}_{4}$ addition. The flow index $\mathrm{n}$ increased for the 3 chemical inhibition techniques in the same order of magnitude (from 0.14 to 0.19 for $\mathrm{HgCl}_{2}$ and $\mathrm{Hg}_{2} \mathrm{SO}_{4}$ and 0.20 for $\mathrm{NaN}_{3}$ ). The apparent viscosity remained constant for the gas purging inhibition indicating no influence on the AS rheological behaviour. However, the nitrogen flow rate has an influence on the apparent viscosity of AS (Fig. 6). A decrease of the apparent viscosity was observed from $3 \mathrm{~L}_{\mathrm{N} 2} \mathrm{~min}^{-1}$ indicating a slight destructuration of AS.

In order to quantify the degree of deflocculation induced by the different inhibition techniques, the supernatant turbidity was measured for initial and inhibited samples (Fig. 7). The results were consistent with the rheological measurements. The gas purging technique did not induce any deflocculation whereas the thermal technique caused the highest deflocculation of all the tested inhibition techniques. The high degree of deflocculation induced 
Table 2

Ostwald law parameters of inhibited AS with five different inhibition techniques.

\begin{tabular}{lllll}
\hline $\begin{array}{l}\text { Inhibition } \\
\text { technique }\end{array}$ & $\begin{array}{l}\text { Concentration } \\
\left(\mathrm{g} \mathrm{gTSS}^{-1}\right)\end{array}$ & $\begin{array}{l}K \\
\left(\mathrm{~Pa} \mathrm{~s}^{\mathrm{n}}\right)\end{array}$ & $\begin{array}{l}K \text { decrease }^{\mathrm{a}} \\
(\%)\end{array}$ & $n$ \\
\hline Initial & - & 0.35 & - & 0.14 \\
$\mathrm{NaN3}$ & 0.2 & 0.31 & $10.7 \pm 0.6$ & 0.20 \\
$\mathrm{Hg}_{2} \mathrm{SO}_{4}$ & 0.1 & 0.22 & $36.6 \pm 1.4$ & 0.19 \\
$\mathrm{HgCl}_{2}$ & 0.03 & 0.31 & $10.7 \pm 0.2$ & 0.19 \\
Gas purging & - & 0.35 & $0 \pm 2.2$ & 0.15 \\
Thermal & - & - & - & - \\
\hline
\end{tabular}

${ }^{a}$ Average and standard deviation based on three measurements.

by the thermal inhibition technique could result from the fact that sludge solids did not solubilise at all into the supernatant. The centrifugation (2 min at $2000 \mathrm{rpm}$ ) carried out to measure supernatant turbidity was not fast enough to bind a significant amount of sludge solids together.

It is noticeable that the deflocculation degree induced by the three chemical inhibitors is similar whereas the reaction duration is much longer for sodium azide $(20 \mathrm{~h})$ than for both mercury inhibitors $(2 \mathrm{~h})$. It confirms that mercury is much more toxic to AS than sodium azide. The evolution of the supernatant turbidity over $20 \mathrm{~h}$ showed that AS deflocculation was limited for sodium azide and mercury sulphate (0.06 absorbance unit) whereas mercury chloride was inducing a high AS deflocculation over time ( 0.16 absorbance unit). This confirms the more toxic nature of mercury (II) cation in comparison to mercury (I) cation. Therefore, $\mathrm{HgCl}_{2}$ might have a higher negative effect to determine sorption properties than $\mathrm{Hg}_{2} \mathrm{SO}_{4}$ depending on the required sorption equilibrium.

The observation of the median size $\left(D_{50}\right)$ of AS flocs for the five inhibition techniques showed that the three chemical inhibitors induced a reduction of the $\mathrm{D}_{50}$ (Table 3 ). $\mathrm{Hg}_{2} \mathrm{SO}_{4}$ caused the most significant $D_{50}$ reduction of the chemical inhibitors with a $D_{50}$ drop-off of $20 \% . \mathrm{HgCl}_{2}$ induced a $15 \%$ decrease of $\mathrm{D}_{50}$ probably due to the lower concentration used, in comparison to $\mathrm{Hg}_{2} \mathrm{SO}_{4}$, to inhibit biomass. Surprisingly, $\mathrm{NaN}_{3}$ effect on $\mathrm{D}_{50}$ was very limited with only a $\mathrm{D}_{50}$ decrease of $6 \%$, whereas $\mathrm{NaN}_{3}$ impacts on the apparent viscosity and the deflocculation degree were identical to $\mathrm{HgCl}_{2}$ impacts. The thermal technique had a drastic effect on the particle size distribution, mainly because of the grinding and the resolubilisation step. The very high $D_{50}$ variability of the thermal inhibition technique shows the lack of homogeneity of the grinding step. Finally, the gas purging technique did not cause any alteration of $D_{50}$. The biomass structure has not been altered at all by this inhibition technique.

\subsection{Effect of the activated sludge inhibition techniques on $\mathrm{pH}$ and conductivity}

$\mathrm{pH}$ and conductivity of initial and inhibited AS were analysed (Table 4) for each inhibition techniques in order to check if the inhibition technique has an impact on these parameters that would disturb the determination of the sorption properties. The $\mathrm{pH}$ variation is not significant since $\mathrm{pH}$ remains approximately neutral for every inhibition technique. A slight increase in the conductivity is observed for $\mathrm{HgCl}_{2}$ and $\mathrm{Hg}_{2} \mathrm{SO}_{4}$ but remains in the same order of magnitude as the initial AS.

$\mathrm{NaN}_{3}$ induces a drastic increase in the conductivity which can be attributed to the high molecular concentration used ( $30.77 \mathrm{~mol} \mathrm{~m}^{-3}$ for $\mathrm{NaN}_{3}, 1.10 \mathrm{~mol} \mathrm{~m}^{-3}$ for $\mathrm{HgCl}_{2}$ and $2.01 \mathrm{~mol} \mathrm{~m}^{-3}$ for $\mathrm{Hg}_{2} \mathrm{SO}_{4}$ ). Therefore, the addition of sodium azide would clearly modify the sorption properties because of the increase in conductivity. Once again, it is noteworthy that the gas purging technique has the lowest effect on both $\mathrm{pH}$ and conductivity.

\subsection{Degradation of easily biodegradable compounds by inhibited activated sludge}

The removal of $800 \mathrm{mg} \mathrm{L}^{-1}$ of COD as glucose and $50 \mathrm{mg} \mathrm{L}^{-1}$ of $\mathrm{NH}_{4}^{+}$were analysed for the five different inhibition techniques

Table 3

D50 values of initial and inhibited AS.

\begin{tabular}{lcc}
\hline Inhibition technique & D50 $(\mu \mathrm{m})$ & D50 decrease $(\%)$ \\
\hline Initial & $87.3 \pm 2.1$ & - \\
Gas purging & $86.6 \pm 1.6$ & 0.8 \\
$\mathrm{NaN}_{3}$ & $81.8 \pm 2.4$ & 6.3 \\
$\mathrm{HgCl}_{2}$ & $74.5 \pm 1.1$ & 14.7 \\
$\mathrm{Hg}_{2} \mathrm{SO}_{4}$ & $69.8 \pm 2.5$ & 20.1 \\
$\mathrm{Thermal}^{\mathrm{a}}$ & $118.7 \pm 31.4$ & -36.0 \\
\hline
\end{tabular}

${ }^{a}$ Average and standard deviation based on three measurements.

Table 4

$\mathrm{pH}$ and conductivity values of initial and inhibited AS.

\begin{tabular}{llc}
\hline Inhibition technique & $\mathrm{pH}$ & Conductivity $\left(\mu \mathrm{S} \mathrm{cm}^{-1}\right)$ \\
\hline Initial & 7.12 & 854 \\
Gas purging & 7.17 & 852 \\
$\mathrm{Hg}_{2} \mathrm{SO}_{4}$ & 6.99 & 930 \\
$\mathrm{HgCl}_{2}$ & 7.37 & 903 \\
$\mathrm{NaN}_{3}$ & 6.97 & 3240 \\
$\mathrm{Thermal}$ & 7.03 & 874 \\
\hline
\end{tabular}

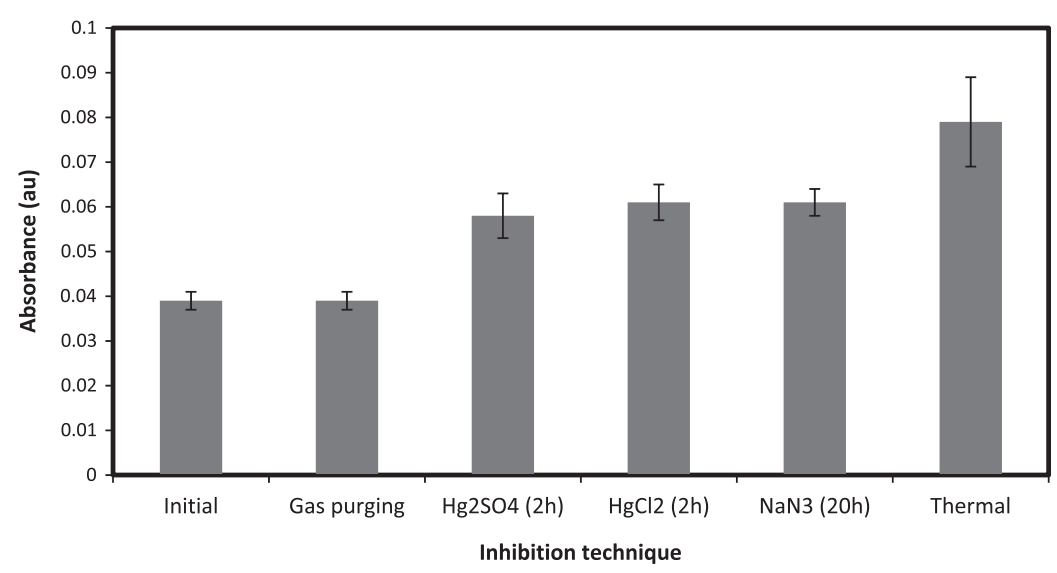

Fig. 7. Supernatant turbidity of initial and inhibited biomass. 
(Table 5). An increase in COD can be observed after $2 \mathrm{~h}$ for every chemical inhibitor. It shows that chemical inhibition leads to a release of soluble microbial products and cell lysis. No COD removal was observed for the thermal and gas purging techniques. Ammonium concentration remained constant for both mercury reagents as well as for the thermal technique whereas a slight degradation was observed for the gas purging technique and sodium azide. The $\mathrm{NH}_{4}^{+}$degradation by sodium azide can be explained by the incomplete achieved inhibition state. One can assume that the residual SOUR after sodium azide application is partially due to autotrophic bacteria, which could perform the nitritation process. Ammonium degradation during the application of the gas purging technique was more surprising because no oxygen was present in the system. Two additional tests with the gas purging technique were performed: a control reactor with only water and $\mathrm{NH}_{4}^{+}$under continuous nitrogen injection; a reactor with AS and $\mathrm{NH}_{4}^{+}$under anaerobic conditions (without the presence of dissolved oxygen in the system) in which nitrogen was only injected at the beginning to force oxygen out. $\mathrm{NH}_{4}^{+}$degradation in water with continuous nitrogen injection was similar to $\mathrm{NH}_{4}^{+}$degradation in AS with continuous nitrogen injection. It pointed out that a reaction of $\mathrm{NH}_{4}^{+}$with $\mathrm{N}_{2}$ occurred. $\mathrm{NH}_{4}^{+}$concentration remained constant in AS under anaerobic conditions and confirmed that $\mathrm{N}_{2}$ reacted with $\mathrm{NH}_{4}^{+}$.

\subsection{Reversibility of the inhibition techniques}

The reversibility of the 5 inhibition techniques was assessed $24 \mathrm{~h}$ after reaching the AS inhibition state by monitoring AS respirometry. Only the gas purging technique allows the recovery of a full AS activity immediately after reinjecting oxygen. No AS respiration could be recovered after inhibition by the thermal technique and both mercury reagents indicate the irreversibility of these inhibition processes causing bacteria decease. A slight AS respiration was observed with $\mathrm{NaN}_{3}$ that can be linked to the incomplete AS state inhibition achieved with this chemical reagent. Therefore, chemical and thermal inhibition techniques cause irreversible damage on AS activity whereas the gas purging technique is the only technique investigated in this study, which allows a totally reversible inhibition process.

Table 5

COD and $\mathrm{NH}_{4}^{+}$removal efficiency for inhibited AS.

\begin{tabular}{lcc}
\hline $\begin{array}{l}\text { Inhibition } \\
\text { technique }\end{array}$ & $\begin{array}{l}\text { COD removal efficiency } \\
(\%)\end{array}$ & $\begin{array}{l}\mathrm{NH}_{4}^{+} \text {removal efficiency } \\
(\%)\end{array}$ \\
\hline Gas purging & 0.0 & 14.3 \\
$\mathrm{Hg}_{2} \mathrm{SO}_{4}$ & -11.4 & -0.7 \\
$\mathrm{HgCl}_{2}$ & -9.9 & 0.9 \\
$\mathrm{NaN}_{3}$ & -8.2 & 23.4 \\
$\mathrm{Thermal}$ & 0.0 & 0.0
\end{tabular}

\subsection{Ranking of the tested activated sludge inhibition techniques}

A recap chart of the adverse effects of the five inhibition techniques on AS structure and mixed liquor chemistry parameters investigated is presented in Table 6. Measurements of the apparent viscosity, the supernatant turbidity and the particle size distribution make it possible to rank the five AS inhibition techniques investigated in this study. The thermal inhibition technique alters drastically the AS structure resulting in a two distinct phases solution with a high floc sizes variability. Indeed, the grinding and the resolubilisation steps of the dried sludge seem crucial to recover the sludge matrix. These two steps are difficult to perform, even being extremely cautious. It explains the impossibility to measure the viscosity at low shear rates (in the laminar region) as well as the large variability of the floc sizes. The thermal inhibition technique is definitely not suitable to assess sorption properties as it damages the floc structure irreversibly. Therefore, sorption of thermally inhibited sludge would absolutely not represent the actual sorption phenomenon occurring in WWTP.

The three chemical inhibitors altered the biomass structure in a more reasonable way than the thermal inhibition. AS was very sensitive to mercury as it is shown by the respiration inhibition kinetics and by the AS structure parameters. Only $2 \mathrm{~h}$ were required to ensure biomass inhibition at low mercury concentration whereas AS inhibition was much more difficult to control with sodium azide: complete AS inhibition has never been achieved and an increase in the $\mathrm{NaN}_{3}$ concentration did not induce a more complete and faster AS inhibition. $\mathrm{NaN}_{3}$ addition involved a very limited decrease of the $\mathrm{D}_{50}$ of the AS flocs. Besides, $\mathrm{NaN}_{3}$ is the only chemical reagent investigated that did not inhibit the nitritation process. One can assume that part of autotrophic bacteria was not inhibited by $\mathrm{NaN}_{3}$ addition which could explain the residual SOUR, being in the same order of magnitude independently of the initial $\mathrm{NaN}_{3}$ concentration. Conversely, the complete and systematic AS inhibition obtained at low mercury concentrations could be the result of the high toxicity effect of mercury on cells. Therefore, mercury induces an important reduction of $D_{50}$ which increases the contact for the reaction between mercury and the bacteria, leading to a full AS inhibition. The significant increase in the supernatant turbidity of AS inhibited with $\mathrm{HgCl}_{2}$ after $20 \mathrm{~h}$ of reaction suggests that $\mathrm{HgCl}_{2}$ alters less AS structure than $\mathrm{Hg}_{2} \mathrm{SO}_{4}$ only within a short time. Therefore, $\mathrm{HgCl}_{2}$ is more suitable than $\mathrm{Hg}_{2} \mathrm{SO}_{4}$ to determine sorption properties immediately after the $2 \mathrm{~h}$ of reaction required for AS inhibition. Depending on the sorption equilibrium time, AS inhibition by $\mathrm{Hg}_{2} \mathrm{SO}_{4}$ would be a better option to limit AS destructuration. After $2 \mathrm{~h}$ of reaction the limited effect of $\mathrm{HgCl}_{2}$, in comparison to $\mathrm{Hg}_{2} \mathrm{SO}_{4}$, on AS apparent viscosity and on the $\mathrm{D}_{50}$ can only be attributed to the lower concentration used. The increase in COD observed for the three chemical reagents after $2 \mathrm{~h}$ of contact with glucose confirmed the achieved inhibition state and the cell lysis induced to the biomass.

Table 6

Recap chart of adverse effects to the biomass structure and the mixed liquor chemistry induced by AS inhibition techniques.

\begin{tabular}{|c|c|c|c|c|c|c|c|c|c|}
\hline Inhibition technique & AS respirometry & Viscosity & Supernatant turbidity & D50 & $\mathrm{pH}$ & Reversibility & COD & $\mathrm{NH}_{4}^{+}$ & Ranking \\
\hline Inhibition technique & AS respirometry & Viscosity & Supernatant turbidity & D50 & $\mathrm{pH}$ & Reversibility & COD & $\mathrm{NH}_{4}^{+}$ & Ranking \\
\hline Gas purging & 1 & 1 & 1 & 1 & 1 & 1 & 1 & - & 1 \\
\hline $\mathrm{NaN}_{3}$ & - & - & - & - & 1 & - & - & - & 3 \\
\hline $\mathrm{HgCl}_{2}$ & 1 & - & - & -- & 1 & - & - & 1 & 2 \\
\hline $\mathrm{Hg}_{2} \mathrm{SO}_{4}$ & I & -- & - & -- & i & - & - & i & 3 \\
\hline Thermal & 1 & -- & -- & -- & 1 & - & 1 & 1 & 5 \\
\hline
\end{tabular}

/ No effect.

-, --, --- Effect degree (from low to high effect). 
$\mathrm{HgCl}_{2}$ seems to be the most appropriate chemical reagent for biomass inactivation as its low required concentration allows limits the adverse effects on the AS structure but only within a short time. In comparison, $\mathrm{NaN}_{3}$ alters AS structure in the same order of magnitude as $\mathrm{HgCl}_{2}$. But the difficulty to achieve a sufficient AS inhibition, which may lead to a degradation of metabolisable compounds by autotrophic bacteria, as well as the longer reaction time required makes $\mathrm{NaN}_{3}$ less appropriate for the determination of sorption properties. However, AS inhibition by $\mathrm{HgCl}_{2}$ will not allow the determination of the exact sorption properties occurring in WWTP.

The gas purging inhibition technique does not induce any effect on the biomass structure. The AS initial properties are kept unchanged after injecting nitrogen in the bioreactor. In addition, this inhibition technique is really easy to implement and, after the aerated and non-aerated phases, the inhibition state is immediately reached as the dissolved oxygen concentration is quasi instantaneously null. Only the nitrogen flow rate must be controlled in order to avoid AS deflocculation. However, it does not consist in a limiting factor since a low nitrogen flow rate is sufficient to quickly force oxygen out. Nevertheless, a gas reaction with the analyte of interest, as observed with nitrogen and ammonium, is possible and would alter the determination of sorption properties. Therefore a reaction of the gas and the analyte of interest must be totally excluded before starting the sorption experiments. The easiest way to avoid this type of reaction would simply consist in determining the sorption properties under anaerobic conditions with an inert gas or without gas injection. Indeed, the gas purging technique only consists in removing the dissolved oxygen from the system, i.e. working under anaerobic conditions. The null dissolved oxygen concentration must be controlled to make sure that there are no biotransformation possibilities since oxygen transfer to biomass might occur because of the required stirring.

However, anaerobic bacteria are not inhibited by the gas purging technique. The anaerobic bacteria fraction in activated sludge of aerobic processes can be considered as negligible because bacteria are always in contact with free and/or bound oxygen in the wastewater treatment plant. Working under anaerobic conditions is therefore appropriated for aerobic AS inhibition. There is no perfect inhibition technique for anaerobic AS. Experiments on anaerobic activated sludge inhibition should focus on chemical inhibition techniques.

\section{Conclusion}

The impact of five different AS inhibition techniques on AS structure was investigated in this study. The results allow to conclude the reliability of these inhibition techniques to determine the sorption properties.

The thermal technique by drying the sludge damages irreversibly the AS structure and is not suitable to assess sorption properties. Chemical inhibition causes adverse effects, which can be limited by determining the lowest effective concentration at which biomass inhibition is ensured. However, AS structure is altered even at low chemical reagents concentrations. Therefore, chemical inactivation, used in many studies, is not appropriate to determine sorption properties because sorption on altered biomass would not represent the real sorption mechanisms. The gas purging technique was the only AS inhibition technique investigated in this study which kept the biomass properties unchanged. However, a reaction between the gas and the analyte of interest might occur which would alter the sorption assessment. The establishment of anaerobic conditions without the use of gas purging avoided the possible reaction of the gas with the investigated pollutant. However, the gas purging technique is not appropriated for anaerobic AS since this technique only consists in forcing the oxygen out of the system. Chemical inhibition by $\mathrm{HgCl} 2$ could be the best compromise for anaerobic AS inhibition.

\section{References}

[1] T.A. Ternes, M.-L. Janex-Habibi, T. Knacker, N. Kreuzinger, H. Siegrist, Assessment of technologies for the removal of pharmaceuticals and personal care products in sewage and drinking water facilities to improve the indirect potable water reuse. POSEIDON, detailed report related to the overall duration. Contract No. EVK1-CT-2000-00047, 2006.

[2] N. Tadkaew, M. Sivakumar, S.J. Khan, J.A. McDonald, L.D. Nghiem, Effect of mixed liquor $\mathrm{pH}$ on the removal of trace organic contaminants in a membrane bioreactor, Bioresour. Technol, 101 (2010) 1494-1500.

[3] E. Barbot, I. Seyssiecq, N. Roche, B. Marrot, Inhibition of activated sludge respiration by sodium azide addition: effect on rheology and oxygen transfer, Chem. Eng. J. 163 (2010) 230-235.

[4] A. Wick, O. Marincas, Z. Moldovan, T.A. Ternes, Sorption of biocides, triazine and phenylurea herbicides, and UV-filters onto secondary sludge, Water Res. 45 (2011) 3638-3652.

[5] L. Clouzot, P. Doumeng, N. Roche, B. Marrot, Kinetic parameters for $17 \alpha-$ ethinylestradiol removal by nitrifying activated sludge developed in a membrane bioreactor, Bioresour. Technol. 101 (2010) 6425-6431.

[6] B. Chefetz, K. Stimler, M. Schechter, Y. Drori, Interactions of sodium azide with triazine herbicides: Effect on sorption to soils, Chemosphere 65 (2006) 352357.

[7] J. Stevens-Garmon, J.E. Drewes, S.J. Khan, J.A. McDonald, E.R.V. Dickenson, Sorption of emerging trace compounds onto wastewater sludge solids. Appendix B: Preliminary inactivation comparisons, Water Res. 45 (2011) 3417-3426.

[8] P. Gaillardon, Influence of soil moisture on long-term sorption of diuron and isoproturon, Pestic. Sci. 47 (1996) 347-354.

[9] T. Yi, W.F. Harper, The effect of biomass characteristics on the partitioning and sorption hysteresis of $17 \alpha$-ethinylestradiol, Water Res. 41 (2007) 1543-1553.

[10] M. Barret, H. Carrère, E. Latrille, C. Wisniewski, D. Patreau, Micropollutant and sludge characterization for modelling sorption equilibria, Environ. Sci. Technol. 44 (2010) 1100-1106.

[11] A.E. Berns, H. Philipp, H.D. Narres, P. Burauel, H. Vereecken, W. Tappe, Effect of gamma-sterilization and autoclaving on soil organic matter structure as studied by solid state NMR, UV and fluorescence spectroscopy, Eur. J. Soil Sci. 59 (2008) 540-550.

[12] J. Chen, X. Huang, D. Lee, Bisphenol A removal by a membrane bioreactor, Process Biochem. 43 (2008) 451-456.

[13] A. Wick, G. Fink, A. Joss, H. Siegrist, T.A. Ternes, Fate of beta blockers and psycho-active drugs in conventional wastewater treatment, Water Res. 43 (2009) 1060-1074.

[14] M. Clara, B. Strenn, E. Saracevic, N. Kreuzinger, Adsorption of bisphenol-A, 17ßestradiole and $17 \alpha$-ethinylestradiole to sewage sludge, Chemosphere 56 (2004) 843-851.

[15] J.Y. Kim, K. Ryu, E.J. Kim, W.S. Choe, G.C. Cha, I. Yoo, Degradation of bisphenol A and nonylphenol by nitrifying activated sludge, Process Biochem. 42 (2007) $1470-1474$.

[16] B. Seyhi, P. Drogui, G. Buelna, J.F. Blais, Removal of bisphenol-A from spiked synthetic effluents using an immersed membrane activated sludge process, Sep. Purif. Technol. 87 (2012) 101-109.

[17] M. Maurer, B.I. Escher, P. Richle, C. Schnaffer, A.C. Alder, Elimination of $\beta$ blockers in sewage treatment plants, Water Res. 41 (2007) 1614-1622.

[18] S.K. Maeng, S.K. Sharma, C.D.T. Abel, A. Magic-Knevez, G.L. Amy, Role of biodegradation in the removal of pharmaceutically active compounds with different bulk organic matter characteristics through managed aquifer recharge: Batch and column studies, Water Res. 45 (2011) 4722-4736.

[19] H. Chen, S. Chen, H. Zhao, Y. Zhang, Sorption of polar and nonpolar organic contaminants by oil-contaminated soil, Chemosphere 73 (2008) 1832-1837.

[20] C. Liang, Z. Dang, B. Xiao, W. Huang, C. Liu, Equilibrium sorption of phenanthrene by soil humic acids, Chemosphere 63 (2006) 1961-1968.

[21] M.A. Chappell, B.E. Porter, C.L. Price, B.A. Pettway, R.D. George, Differential kinetics and temperature dependence of abiotic and biotic processes controlling the environmental fate of TNT in simulated marine systems, Mar. Pollut. Bullet. 62 (2011). pp. 1736-17.

[22] L. Delgado, Bioréacteur à membrane externe pour le traitement d'effluents contenant des médicaments anticancéreux: élimination et influence du cyclophosphamide et de ses principaux métabolites sur le procédé. Thèse Génie des Procédés, INP Toulouse, 2009. <http://ethesis.inp-toulouse.fr/ archive/00000816/01/delgado.pdf>.

[23] H.R. Andersen, M. Hansen, J. Kjølholt, F. Stuer-Lauridsen, T. Ternes, B. HallingSørensen, Assessment of the importance of sorption for steroid estrogens removal during activated sludge treatment, Chemosphere 61 (2005) 139-146.

[24] T. Ternes, N. Hermann, M. Bonerz, T. Knacker, H. Siegrist, A. Joss, A rapid method to measure the solid-water distribution coefficient $\left(K_{D}\right)$ for pharmaceuticals and musk fragrances in sewage sludge, Water Res. 38 (2004) 4075-4084.

[25] J. Seira, C. Sablayrolles, M. Montrejaud-Vignolles, H. Carrere, D. Patureau, C.Albasi, C. Joannis-Cassan, Quantification de l'adsorption de molécules 
médicamenteuses (anticancéreuses) sur des boues biologiques: impact de la nature des boues. Personnal communication, Congrès SFGP Lille, 2011.

[26] M. Hörsing, A. Ledin, R. Grabic, J. Fick, M. Tysklind, J.C. Jansen, H.R. Andersen, Determination of sorption of seventy-five pharmaceuticals in sewage sludge, Water Res. 45 (2011) 4470-4482.
[27] I. Seyssiecq, B. Marrot, D. Djerroud, N. Roche, In situ triphasic rheologica characterisation of activated sludge, in an aerated bioreactor, Chem. Eng. J. 142 (2008) 40-47.

[28] B.M. Wilén, K. Keinding, P.H. Nielsen, Flocculation of activated sludge flocs by stimulation of the aerobic biological activity, Water Res. 38 (2004) 3909-3919. 